\title{
Growth of Bi-Sb Alloy Single Crystals
}

\author{
Leistiko, Otto; Lindegaard-Andersen, Asger
}

Published in:

Journal of Applied Physics

Link to article, DOI:

$10.1063 / 1.1657248$

Publication date:

1969

Document Version

Publisher's PDF, also known as Version of record

Link back to DTU Orbit

Citation (APA):

Leistiko, O., \& Lindegaard-Andersen, A. (1969). Growth of Bi-Sb Alloy Single Crystals. Journal of Applied Physics, 40(11), 4659-4660. https://doi.org/10.1063/1.1657248

\section{General rights}

Copyright and moral rights for the publications made accessible in the public portal are retained by the authors and/or other copyright owners and it is a condition of accessing publications that users recognise and abide by the legal requirements associated with these rights.

- Users may download and print one copy of any publication from the public portal for the purpose of private study or research.

- You may not further distribute the material or use it for any profit-making activity or commercial gain

- You may freely distribute the URL identifying the publication in the public portal

If you believe that this document breaches copyright please contact us providing details, and we will remove access to the work immediately and investigate your claim. 
In summary:

(1) Epitaxial gold and silver films containing a low planar defect density $\left(\sim 10^{3}\right.$ to $\left.10^{6} \mathrm{~cm}^{-2}\right)$ can be grown from the vapor by subjecting the rocksalt substrates to an annealing and surface wetting treatment after cleavage, if low substrate temperatures $\left(\sim 200^{\circ} \mathrm{C}\right)$ and high evaporation rates are used.

(2) Gold films, with presumably reduced gaseous impurity contents, can be obtained by depositing gold epitaxially under UHV conditions onto previously prepared epitaxial silver layers.

(3) Relatively perfect single crystal epitaxial sandwiches (consisting of silver, gold, platinum or palladium layers) can be produced by successive evaporation onto silver or gold substrates. In all cases epitaxial growth is observed at substrate temperatures of $\sim 200^{\circ} \mathrm{C}$.

The author wishes to thank Professor R. W. Balluffi for his encouragement and for critically reading the manuscript. Helpful discussions with Professor D. N. Seidman are also acknowledged.

* This work was supported by the U. S. Atomic Energy Commission. Additional support was received from the Advanced Research Projects Agency through the use of the technical facilities of the Materials Science Center at Cornell University.

${ }_{1}$ H. Lassen and L. Brück, Ann. Phys. 22, 65 (1935); ibid. 26, 233 (1936).

2 D. W. Pashley, Advan. Phys. 5, 173 (1956); Phil. Mag. 4, 316 (1959).

${ }^{3}$ D. W. Pashley and M. J. Stowell, Phil. Mag. 8, 1605 (1963)

4 H. Bethge and M. Krohn, Int. Symp. Basic Problems Thin Films Phys., Clausthal-Göttingen, Sept. 1965.

s S. Shinozaki and H. Sato, J. Appl. Phys, 36, 2320 (1965).

J. W. Matthews and E. Grünbaum, Phil. Mag. 11, 1233 (1965).

${ }^{7}$ L. E. Murr and M. C. Inman, Phil. Mag. 14, 135 (1966).

${ }^{8}$ E. Bauer, A. K. Green, and K. M. Kunz, Appl. Phys. Lett. 8, 248 (1966).

K. M. Kunz, A. K. Green, and E. Bauer, Phys. Status Solidi 18, 441 (1966).

${ }^{10}$ C. A. O. Henning, Surface Sci. 9, 277 (1968); ibid. 9, 296 (1968).

11 No recrystallization of the silver occurred as a result of this treatment. (It is frequently observed that a single crystal epitaxial film is converted into a polycrystal upon heating to an elevated temperature while on its substrate.)

${ }^{12}$ E. W. Dickson, M. H. Jacobs, and D. W. Pashley, Phil. Mag. 11, 575 (1965).

13 T. Schober and R. W. Balluff, Phys. Status Solidi 27, 195 (1968).

\section{Growth of Bi-Sb Alloy Single Crystals}

\author{
O. Leistiko, JR., AND A. LindegaARD ANDERSEN \\ Physical Laboratory III, The Technical University of Denmark, \\ Lyngby, Denmark \\ (Received 12 June 1969)
}

Growth of $\mathrm{Bi}_{1-x} \mathrm{Sb}_{x}(0 \leq x \leq 0.3)$ alloy single crystals by the zone-melting technique has recently been investigated by several
TABLE I. Melting parameters of Bi-Sb alloys. A value of $q>2$ indicates that the $\{100\}$ planes at the solid-liquid interface are singular.

\begin{tabular}{lllll}
\hline \hline Sb at.\% & 0 & 8.3 & 16 & 30.7 \\
\hline$\Delta H \mathrm{kcal} / \mathrm{mole}$ & 2.70 & 4.26 & 4.54 & 4.46 \\
$\Delta H / k T_{E}$ & 2.5 & 3.9 & 4.1 & 3.9 \\
$q\{100\}$ & 1.7 & 2.6 & 2.7 & 2.6 \\
\hline
\end{tabular}

authors. ${ }^{1-5}$ Considering the effect upon microstructural homogeneity of various growth parameters, it has been concluded that constitutional supercooling is the most important factor. ${ }^{5}$ In the present communication we would like to call attention to two other important factors which, hitherto, do not seem to have been considered, namely, the possible existence of singular planes and the subsequent development of a layered structure at the growth interface.

According to Jackson ${ }^{6}$ a plane solid-liquid interface is singular if $q=\Delta H w / k T_{E^{v}}>2$, where $\Delta H$ is the latent heat of fusion, $k$ is the Boltzmann constant, $T_{E}$ is the melting point temperature, $w$ is the number of nearest neighbors to an atom lying in the interface, and $v$ is the total number of nearest neighbors of an atom situated in the interior of the crystal.

$\mathrm{Bi}$ and $\mathrm{Bi}-\mathrm{Sb}$ alloy crystals have rhombohedral structures, each atom having three nearest neighbors. Since $v=3$ the value of $w / v$ cannot be greater than $\frac{2}{3}$. This value occurs for the $\{100\}$ planes (using pseudocubic notation). The $q$ values for these planes based on experimental values of $\Delta H$ (Ref. 7) for Bi-Sb alloys of various compositions are given in Table $I$. We note that in alloys having antimony concentrations greater than a few atomic percent the value of $q$ is greater than 2 and, therefore, the possibility for the formation of an interface with $\{100\}$ facets exists. Further, under the proper conditions a "layered structure," composed of singular faces represents the stable morphology of the growth interface. In addition, such a layered growth may give rise to periodic variation in the solute concentration. In the present case, where the segregation coefficient is greater than 1 , we expect a lower solute concentration at the boundaries of the facets. This sort of behavior has been reviewed by Tiller $^{8}$ and discussed by Trainor and Bartlett. ${ }^{9}$

Support to these conclusions has been given by a series of $\mathrm{Bi}_{1-x} \mathrm{Sb}_{x}(x=0,0.07,0.15)$ crystal growth experiments. An example of the results obtained when growth of a $\mathrm{Bi}_{0.85} \mathrm{Sb}_{0.15}$ crystal was suddenly stopped by decanting the molten zone is shown in Fig. 1. The large and highly developed facets are $\{100\}$ planes, as determined by $x$-ray analysis. Because of the growth conditions, the slow growth rate $R=1 \mathrm{~mm} / \mathrm{h}$ and rather large temperature gradient $G=55^{\circ} \mathrm{C} / \mathrm{cm}$ we exclude the possibility of dendritic growth entirely and at most expect only a limited cellular growth

FiG. 1. Layered structure of the decanted interface of a $\mathrm{Bi}_{0.85} \mathrm{Sb}_{0.15}$ alloy single crystal. The plane of the view shown here is perpendicular to the axis of the ingot. X-ray analyses showed that the facets are $\{100\}$ planes.

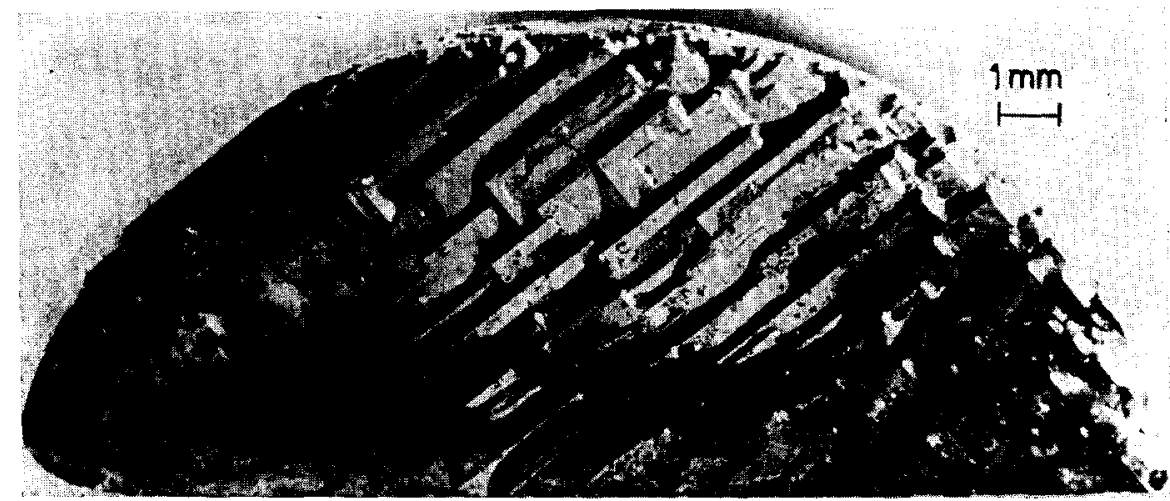




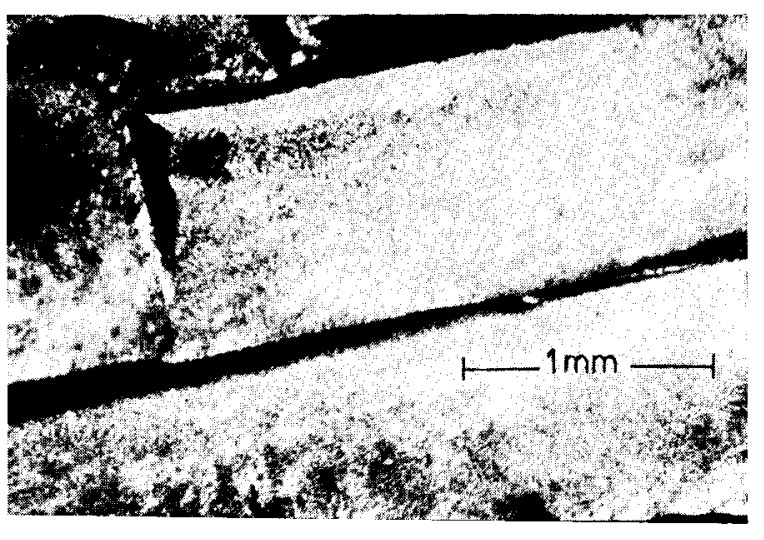

FiG. 2. The structure contained within the facets as revealed by etching. When viewed with higher magnification the fine structure appeared to have an orientation lying nearly in the $\{111\}$ planes.

arising from the small constitutional supercooling present. Subsequent etching of this crystal revealed a pox-like structure within the large facets, which we associate with limited cellular growth (see Fig. 2). The etching behavior further suggested that the boundaries between the facets were bismuth rich. Electron microprobe investigations on this and other, similar, crystals verified the existence of bismuth-rich regions between the facets, although not conclusively. The morphology of the decanted interface of a $7 \mathrm{at} . \% \mathrm{Sb}$ alloy is similar to that of the $15 \mathrm{at} \% \mathrm{Sb}$ alloy but, with somewhat smaller facets. No $\{100\}$ facets were observed on pure bismuth crystals grown under similar conditions, which is in accordance with the fact that the value of $q$ is less than 2. It should be mentioned here that the theory outlined above suggests also that the faceted structure interface and consequent segregation of the solute can be eliminated by making the growth interface concave toward the liquid. This has been observed to be the case.

We conclude, then, that the possible existence of a singular interface in melt-grown bismuth-antimony alloy crystals may be one of the most important factors affecting the homogeneity of these crystals, and if constitutional supercooling can be excluded, this phenomenon is second only to the effect of thermal fluctuations in determining the homogeneity.

The assistance of Mr. S. Ipsen Mathiesen in connection with the performance of the $\mathrm{x}$-ray analyses and Miss $\mathrm{K}$. Rasmussen with the crystal growth is gratefully acknowledged.

ID. A. Brown and F. K. Heumann, J. Appl. Phys. 35, 1947 (1964).

2 M. A. Short and J. J. Schott, J. Appl. Phys. 36, 659 (1965).

${ }^{3}$ M. Dugué, Phys. Status Solidi 11, 149 (1965).

4 J. P. Dismukes and L. Ekstrom, Trans. Met. Soc. AIME 233, 672 (1965).

¿ W. M. Yim and J. P. Dismukes, Proc. Int. Conf. Cryst. Growth, Boston, 1966 (Suppl. J. Phys. Chem. Solids) 187 (1967).

" K. A. Jackson, "Liquid Metals Solidification," Seminar 39th Nat. Metal Congr. Cleveland, 1958 (Amer. Soc. Metals, Cleveland, 1958), p. 174.

${ }^{7}$ Gmelin's Handbuch der Anorganischen Chemie, Wismut (Verlag Chemie, GMBH, Weinheim/Bergstr., 1964) p. 612 .

8 W. A. Tiller in The Art and Science of Growing Crystals, J. J. Gilman, Ed. (J. Wiley \& Sons, Inc., New York, 196.3) p. 290.

${ }^{9}$ A. Trainor and B. E.. Bartlett, Solid-State Electron. 2, 106 (1961).

\section{Crystal Growth of $2 H$ Silicon Carbide}

J. Anthony Powel.

National Aeronautics and Space Administration, Lewis Research Center, Cleveland, Ohio 44135

(Received 21 April 1969; in final form 30 June 1969)

$2 H \mathrm{SiC}$ is a semiconductor with possible advantages over the more common $\alpha$-SiC polytypes. It can be grown ${ }^{1-5}$ at temperatures less than $1500^{\circ} \mathrm{C}$, which offers obvious advantages over the much higher temperatures required by the usual sublimation growth of $\alpha$-SiC crystals. ${ }^{6}$ It has the largest energy band gap of all the known $\mathrm{SiC}$ polytypes and this could be desirable in some applications. Also, considerations of electron scattering mechanisms in $\mathrm{SiC}^{7}$ indicate that the electron mobility in $2 H$ SiC should be higher than the $6 H$ and $15 \mathrm{R}$ polytypes. Yet, to date, not much work has been done to determine the crystal growth mechanism and the optimum conditions for the growth of $2 \mathrm{H} \mathrm{SiC}$. In an attempt to get this information, crystals of $2 \mathrm{H}$ SiC were grown at the Lewis Research Center. This paper describes factors which affected this crystal growth and presents evidence which indicates that the major portion of each crystal was grown by a vapor-solid mechanism.

Wagner and Ellis ${ }^{8}$ have suggested the VLS mechanism to explain the growth of $2 H \mathrm{SiC}$. On the basis of their experiments Ryan et al ${ }^{4}$ concluded that their $2 H$ whiskers grew via the VLS mechanism. In similar fashion, Patrick et al..$^{3}$ grew $2 H$ whiskers, but they stated that the VLS mechanism did not appear to provide an explanation for their growth. In a recent paper, Knippenberg and Verspui ${ }^{5}$ indicated that impurities were necessary in the growth of $2 H \mathrm{SiC}$. Although it was not clear whether the VLS mechanism was involved in their $2 H$ growth, they did demonstrate the VLS growth of $\beta$-SiC and some $\alpha$-SiC polytypes.

The process used in this work was similar to that used by others $^{1,3}$ in the growth of $2 H \mathrm{SiC}$. Hydrogen was mixed with methyltrichlorosilane $\left(\mathrm{CH}_{3} \mathrm{SiCl}_{3}\right)$ vapor and then passed over an inductively heated susceptor inside a quartz reaction tube. With

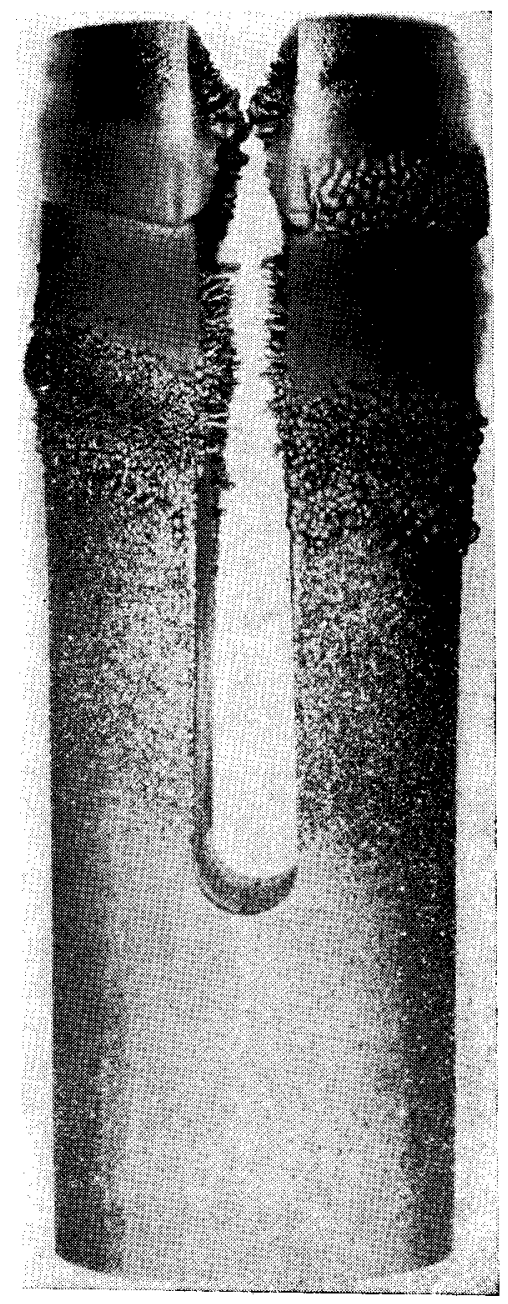

FIG. 1. Typical susceptor showing bands of deposition. 